\title{
Optimal Macroprudential Policy and Asset Price Bubbles*
}

\author{
Nina Biljanovska ${ }^{1}$, Lucyna Górnicka ${ }^{1}$, and Alexandros Vardoulakis ${ }^{2}$ \\ ${ }^{1}$ International Monetary Fund \\ ${ }^{2}$ Federal Reserve Board
}

February 14, 2019

\begin{abstract}
An asset bubble relaxes collateral constraints and increases borrowing of credit-constrained agents. At the same time, as the bubble deflates when constraints start binding, it amplifies downturns. We show analytically and quantitatively that the macroprudential policy should optimally respond to building asset price bubbles in a non-linear fashion depending on the underlying indebtedness. If credit is moderate, policy should accommodate the bubble to reduce the incidence of binding collateral constraints. If credit is elevated, policy should lean against the bubble more aggressively to mitigate the pecuniary externalities from a deflating bubble when constraints bind.
\end{abstract}

JEL Classification: E2, E44, G1

Keywords: Collateral constraints, rational bubbles, macroprudential regulation, optimal policy

${ }^{*}$ The views expressed in this paper are those of the authors and do not necessarily represent those of the IMF, the Federal Reserve Board, or anyone in the Federal Reserve System. We thank Bora Durdu, Raphael Espinoza, Olamide Harrison, Narayana Kocherlakota, Ivan Werning, and seminar participants at the IMF, Federal Reserve Board, University of Toronto and the 2nd Annual NuCamp Conference Oxford for their comments and suggestions. 


\section{Introduction}

In the aftermath of the global financial crisis (GFC), policymakers and academics widely shared the view that policy should "lean against" financial imbalances. As a result, new "macroprudential" instruments to tackle credit growth have been introduced in many countries, including a counter-cyclical capital buffer for banks, and loan-to-value ratios for housing loans.

At the same time, surges in credit growth are often accompanied by hikes in asset prices, and interplay between the two has been shown to have large economic effects. For example, Mishkin (2011) and Jordà, Schularick and Taylor (2015) argue that credit-fueled asset price bubbles are more dangerous for financial stability and economic growth than bubbles not followed by debt build-ups. Fostel and Geanakoplos (2008) and Adrian and Shin (2009) show that the feedback loop between asset prices and credit can lead to a procyclical leverage and to financial instability. Yet, despite the growing empirical evidence, there is no broadly accepted view if macroprudential policy should respond to asset price increases beyond its response to credit growth (Barlevy (2018)) [1 In particular, at least until recently, the modelling difficulties related to incorporating asset price bubbles into theoretical models have made such models not well-suited for answering policy-related questions $2^{2}$

We contribute to this discussion by proposing a theoretical framework that integrates a meaningful policy analysis into a model of asset price overvaluations. We use this framework to study the following questions. Should macroprudential policy respond to asset price overvaluations over and beyond its role to tackle excessive credit growth? If yes, should macroprudential policy be more aggressive or more accomodative? Does the policy response depend on the level of credit in the economy? These considerations are not only of theoretical interest, but also of practical relevance as financial imbalances preceding crisis episodes may or may not be accompanied by overvaluations in asset prices. Figure 1 plots the credit-

\footnotetext{
${ }^{1}$ We focus here on macroprudential policies targeting credit and consider bubbles in this context. Besides their impact on credit, bubbles can be a source of other types of risk, such as outsized drops in asset prices ("fire-sales") when they deflate.

${ }^{2}$ Also the difficulty in identifying overvaluations has made many policy-makers reluctant to automatically react to rapid price growth. This issue is, arguably, less concerning in the aftermath of the GFC, as policymakers and academics have put a lot of effort to detect "valuation pressures" in asset prices. Some examples include the Office of Financial Research's Financial System Vulnerabilities Monitor, and the Shiller's CAPE index (Cyclically Adjusted Price Earnings).

${ }^{3}$ We define asset price overvaluation as a positive deviation of the market price from its fundamental value.
} 
to-GDP gap (a measure of credit imbalances) and a composite index of house and equity price overvaluations for the United States. Credit growth was excessive both before the 1987 and the 2008 systemic crises, but only in the latter case it was accompanied by overvalued asset prices. Moreover, asset price overvaluations can emerge even when credit is subdued, such as before the dot-com bubble in the early 2000s and-more strikingly-since 2014.

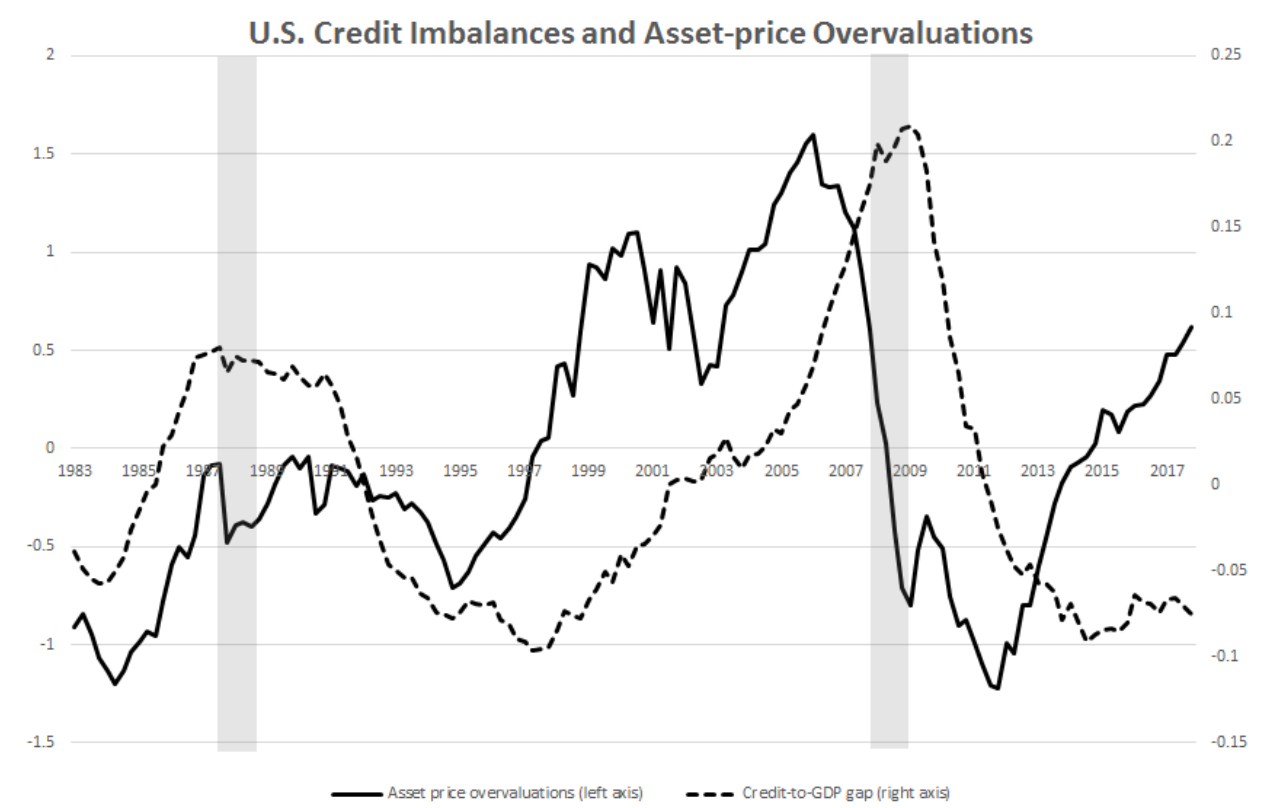

Figure 1: U.S. Credit Imbalances and Asset Price Overvaluations.

Notes: The figure plots the credit-to-GDP gap and a measure of asset-price overvaluations for the U.S. from 1983 to 2018. The shaded-gray areas corresponds to the systemic crisis of 1987 and 2008 identified in Laeven and Valencia (2012). The credit-to-GDP gap is computed based on a smooth trend obtained through the Hodrick-Prescott filter with a smoothing parameter $\lambda=$ 400, 000 (after Basel Committee's guidelines for setting the counter-cyclical capital buffer). Large positive (negative) values indicate excessive (subdued) credit. The asset price overvaluations index is a composite of overvaluations in equity and house prices computed as the percentiles of the price-to-earnings and price-to-rent ratios in the historical distributions for S\&P 500 firms and the nationwide housing market, respectively.

To answer the aforementioned questions, we augment the Miao and Wang (2018) model of stock price bubbles, to allow for occasionally binding collateral constraints á la Bianchi and Mendoza (2018). In the model, firms want to borrow abroad for production purposes, but their borrowing ability is limited. The constraint arises endogenously as a result of a limited commitment problem similar to Jermann and Quadrini (2012). A stock price bubble can relax the credit constraint by raising the value to a firm of not defaulting on its liabilities. As a result, firms can borrow more to finance production, supporting higher firm 
value, higher dividends, and higher consumption. We show analytically that the optimal macroprudential policy rule changes in the presence of the bubble, and employ global solution methods to show quantitatively that the policy response to bubbles is economically meaningful ${ }^{4}$

In contrast to frameworks with always binding financial frictions (Bernanke, Gertler and Gilchrist (1999) and Kiyotaki and Moore (1997)), occasionally binding constraints introduce a nonlinear feedback loop between asset prices and borrowing capacity. As atomistic agents take asset prices as given, they neglect the price effects of their actions. When constraints bind, agents are forced to deleverage and cut consumption, which adversely affects asset prices that grow with consumption via the typical Euler equation. This is the source of a pecuniary externality introducing a wedge between private and socially optimal outcomes $5^{5}$ Contrary to private agents, the social planner internalizes how the decision to take on more debt may affect current and future prices. The optimal policy takes the usual form of a (Pigouvian) tax on borrowing.

However, the exact policy prescription to tackle the externality depends on whether constraints are always binding or not. If financial frictions bind, then it is not obvious whether agents would be better-off by restricting or encouraging more borrowing. Higher borrowing exposes the economy to a higher risk of deleveraging and tighter constraints in the future, but at the same time it boosts current asset prices and relaxes today's constraints. In contrast, in the presence of occasionally binding constraints, a pure macroprudential tax would only target the externalities generated by binding constraints in the future and would be imposed ex-ante when agents are not constrained in order to lean against excessive credit growth. As Bianchi and Mendoza (2018) show, such a macroprudential tax on borrowing is always positive.

Our paper shows that the non-linearity introduced by occasionally binding constraints generates a key policy trade-off when asset price bubbles are considered. On the one hand, bubbles can completely relax the collateral constraint and, hence, alleviate downturns for some shock realizations. This can be thought of as an extensive margin through which bubbles affect real outcomes. On the other hand, bubbles deflate faster when the collateral constraint binds, which gen-

\footnotetext{
${ }^{4}$ Miao, Wang and Zhou (2015) also study optimal policy in the presence of bubbles, yet under always binding credit constraints. As we argue, the conclusions can be sharply different when the credit constraints are allowed to bind only at times.

${ }^{5} \mathrm{~A}$ growing body of literature has proposed pecuniary externalities as a rationale for ex-ante policy interventions. See also, for example, Lorenzoni (2008), Jeanne and Korinek (2010), and Korinek (2011).
} 
erates pecuniary externalities and, hence, exacerbates the downturn. This can be thought of as an intensive margin. The social planner weighs the relative strength of the extensive and intensive margins to determine the optimal policy response. If the extensive margin dominates, then the planner would want to encourage borrowing-or lean against credit growth less aggressively-in order to boost current and future bubble prices and reduce the probability that the collateral constraint binds in the future. On the contrary, if the intensive margin dominates, then the planner would want to lean against credit growth more aggressively to mitigate pecuniary externalities from deflating bubbles. In other words, for the same level of credit imbalances, as measured for example by the credit-to-GDP gap, the planner sets a higher (lower) macroprudential tax on borrowing when the intensive (extensive) margin dominates compared to the bubbleless economy.

This optimal policy trade-off raises the question whether one margin always dominates the other or whether their relative strength depends on the underlying economic conditions. We show quantitatively that the intensive margin dominates when credit is high, while the extensive margin is stronger for moderate levels of credit. Intuitively, when credit is not elevated, bubbles can more easily relax (marginally binding) collateral constraints, while the pecuniary externalities when constraints bind are not so severe because agents do not need to deleverage from high levels of debt. The opposite is true for high levels of indebtedness.

Hence, our results suggest that macroprudential regulation, such as the countercyclical capital buffer or LTV limits, should explicitly incorporate asset price overvaluations, but not always to justify stricter regulation. For moderate levels of debt, overvalued assets, which can act as collateral, alleviate financial frictions and macroprudential policy should be more accommodative. Finally, we show that when credit is very low, the macroprudential policy should be kept lax, irrespectively of the presence of bubbles, which corroborates the empirical evidence that creditless bubbles are less dangerous.

The rest of this paper is organized as follows. Section 2 presents the baseline model. We analyze optimal policy in section 3. We show the numerical results in section 4. Finally, section 5 concludes.

Related Literature. Our paper is closest in spirit to the model of rational bubbles in Miao and Wang (2018), which we augment to allow for occcasionally binding credit constraints. In the model, maximum borrowing depends on the firm's (market) value, and a bubble on the firm's stocks relaxes the constraint, increasing borrowing capacity of the economy. In terms of optimal policy analysis, we follow 
the approach of Bianchi and Mendoza (2018) and analyze the implications of the bubble for macroprudential tools. Contrary to Miao and Wang (2018) who allow for capital accumulation, in our framework capital is in fixed supply as in Bianchi and Mendoza (2018). Yet, we still consider a bubble on a productive asset in an infinite horizon production economy with financial frictions (see Scheinkman and Weiss, 1986; Kocherlakota 1992, 2008; Santos and Woodford, 1997 for bubbles in infinite-horizon endowment economies with borrowing constraints).

The recent literature on bubbles focuses conditions under which they can emerge in equilibrium and their implications for real outcomes. In Miao, Wang and Zhou (2015) a bubble on otherwise useless land can exist only if the probability of a bubble burst is sufficiently low and if land has a high value as a collateral for loans. Hirano and Yanagawa (2017) show that the effects of a bubble burst depend on the degree of pledgeability of the bubbly asset. In Aoki and Nikolov (2015), Bengui and Phan (2018) the level of interest rates, agents' leverage, and the degree pledgeability affect who holds the bubble in equilibrium and whether the bubble is financed by borrowing. Chauvin, Laibson and Mollerstrom (2011) find that in the absence of financial frictions bubbles are always welfare-reducing as they magnify cyclical fluctuations of consumption. On the contrary, Hirano and Yanagawa (2017) study bubbles in an endogenous growth model with borrowing constraints and show that bubbles can increase welfare, regardless of the effects of their bursts, as they relax the financial friction and allow for consumption-smoothing by creditconstrained agents. Many other papers study the existence and implications of pure bubbles, i.e., bubbles on intrinsically useless assets, which relax borrowing constraints (Caballero and Krishnamurthy, 2006; Farhi and Tirole, 2012; Kiyotaki and Moore, 2012; Martin and Ventura, 2012).

In terms of policy advice, Miao, Wang and Zhou (2015) find that loan-to-value limits and a property transaction tax can reduce the benefits of holding the bubbly asset, while Miao and Wang (2015) suggest that increasing bank capital requirements can prevent bubbles held by the financial sector. In comparison, we focus on optimal policy response to already existing bubbles, i.e. when policymakers cannot prevent bubbles from emerging. Moreover, our macroprudential policy tool targets inefficiencies arising from occasionally binding collateral constraints. In contrast, Miao, Wang and Zhou (2015) derives policy for collateral constraints that are always binding.

We also contribute to the growing literature on macroprudential policy. The need for a policy intervention is usually motivated by the presence of financial frictions and pecuniary externalities, which magnify the effects of aggregate shocks 
(Stein, 2012; Bianchi, 2011; Jeanne and Korinek, 2010). Alternatively, the inefficiencies are generated through a depressing impact of debt deleveraging on aggregate demand in a setup with agent heterogeneity with respect to their marginal propensity to consume (Eggertsson and Krugman, 2012; Korinek and Simsek, 2016, Farhi and Werning, 2016 ).

\section{Model economy}

The economy we study incorporates a rational bubble on a productive asset in a small open economy model with occasionally binding collateral constraints. The modeling of the rational bubble follows Miao and Wang (2018), who show that a rational stock price bubble can be supported in equilibrium in production economies with infinitely lived agents. We proceed by first outlining the competitive economy (CE) equilibrium allocations. Subsequently in section 3 , we analyze time-consistent optimal policy plans following Bianchi and Mendoza (2018) - Bianchi-Mendoza hereafter — and derive the optimal macroprudential policy tax on borrowing that implements the planner's allocations in the decentralized economy.

\subsection{Small open economy with an asset price bubble}

The infinite-horizon production economy is populated by a continuum of identical households and a continuum of identical firms. Households consume, provide labor services, and are the owners of firms. They can also frictionlessly trade firm shares at the stock market. Firms own a production technology, which combines capital, labor and intermediate goods as inputs to production. They purchase and sell capital and can borrow internationally at inter-temporal debt markets. In what follows we define households' and firms' optimization problems and derive the competitive equilibrium.

Households. A representative household lives for infinite periods and maximizes the expected utility, which is a function of consumption $c_{t}$ and labor $l_{t}$

$$
\max _{c_{t}, l_{t}, \eta_{t+1}} E_{t} \sum_{t=0}^{\infty} \beta^{t} U\left(c_{t}-G\left(l_{t}\right)\right),
$$


subject to the budget constraint

$$
c_{t}+\int_{j} V_{t}^{j} \eta_{t+1}^{j} d j=\int_{j} V_{t}^{j} \eta_{t}^{j} d j+\int_{j} D_{t}^{j} \eta_{t+1}^{j} d j+w_{t} l_{t},
$$

where $V_{t}^{j}$ denotes firm $j$ 's cum-dividend equity value, and $D_{t}^{j}$ is firm $j$ 's dividend paid out in period $t$. The household starts the period with $\eta_{t}^{j}$ shares of firm $j$, which it can trade at the stock market for shares of other firms. As a results, its end-period holdings of firm $j$ 's equity are $\eta_{t+1}^{j}$. In addition to dividends, the household earns income from wages, denoted by $w_{t}$ for labor supplied to firms. The utility function $U(\cdot)$ is a standard concave, twice-continuously differentiable in both its arguments and satisfies the Inada conditions. Preferences are defined over $c_{t}-G\left(l_{t}\right)$, a composite commodity, where $G\left(l_{t}\right)$ is a convex function, strictly increasing and continuously differentiable.

The first-order optimality conditions of the household read

$$
\lambda_{t}=U_{c, t}
$$

$$
w_{t}=G_{l, t},
$$

$$
V_{t}^{j}=\beta E_{t}\left(\frac{U_{c, t+1}}{U_{c, t}} V_{t+1}^{j}\right)+D_{t}^{j}
$$

where $\lambda_{t}$ is the Lagrange multiplier corresponding to the budget constraint (2), and $J_{x, t}$ denotes a first-order derivative of a function $J$ with respect to variable $x_{t}$. Equation (5) implies that the return on a firm's equity is equal to the household's stochastic discount factor $\beta E_{t}\left(\frac{U_{c, t+1}}{U_{c, t}}\right)$. Iterating forward and using that in equilibrium $\int_{j} \eta_{t}^{j} d j=1$, yields the following transversality condition:

$$
\lim _{T \rightarrow \infty} \beta^{T} \frac{U_{c, T}}{U_{c, t}} V_{T}^{j}=0
$$

Firms. As all firms are the same in equilibrium, we explain the problem of a representative firm and drop the superscript $j$ for notation simplicity. Following Miao and Wang (2018), we assume that firm's management acts in the best interest of shareholders (households) to maximize the market value of the firm 


$$
V_{t}\left(k_{t}, L_{t}\right)=\max D_{t}+\beta E_{t}\left(\frac{U_{c, t+1}}{U_{c, t}} V_{t+1}\left(k_{t+1}, L_{t+1}\right)\right)
$$

where the two state variables are the stock of capital, $k_{t}$, and debt, $L_{t}$, from the last period.

The firm produces $y_{t}=z_{t} F\left(k_{t}, l_{t}^{d}, v_{t}\right)$ each period. The function $F(\cdot)$ is CobbDouglas and combines labor $l_{t}^{d}$ with the stock of capital purchased last period, $k_{t}$, and an intermediate good $v_{t} ; z_{t}$ is an aggregate productivity shock. Capital is in unit fixed supply: $K_{t}=1$. Intermediate goods are traded in competitive world markets at a fixed exogenous price $p_{v}$. The profits of the firm are distributed as dividends, $D_{t}$, to its shareholders (households). The budget constraint of the firm is given by

$$
D_{t}=y_{t}-p^{v} v_{t}-w_{t} l_{t}^{d}+\frac{L_{t+1}}{R}-L_{t}+q_{t} k_{t}-q_{t} k_{t+1}
$$

where $L_{t}$ denotes the holding of one-period non-state contingent foreign bonds, $q_{t}$ is the price of capital, and $R$ is the world-determined gross real interest rate taken as given by the small open economy.

Similar to Bianchi and Mendoza (2018) and Jermann and Quadrini (2012), we assume that a portion $\theta \leq 1$ of the inter-mediate good $p_{v} v_{t}$ needs to be financed ahead of production. Thus, the total liabilities of the firm in the beginning of period comprise of $\theta p_{v} v_{t}+\frac{L_{t+1}}{R}$. While $L_{t+1}$ is an inter-temporal loan, $\theta p_{v} v_{t}$ is repaid within the same period and hence it does not bear any interest. Assuming there is a limit on the obligations to the firm, the maximum amount that can be borrowed by the firm is bounded by a collateral given by

$$
\frac{L_{t+1}}{R_{t}}+\theta p^{v} v_{t} \leq m_{t} V_{t+1}\left(k_{t}, 0\right)
$$

Constraint (9) limits the size of total debt to a fraction $m_{t}$ of the firm's continuation value in the case when the firm defaults on its obligations. In the Appendix A.1 we derive the collateral constraint as an incentive compatibility constraint arising from a renegotiation of debt problem between borrowers and lenders similar to Jermann and Quadrini (2012). Following Miao and Wang (2018), we assume that creditors seize the entire firm, which is valued at equity markets, rather than seizing the firm's capital stock as in Jermann and Quadrini (2012). This matters 
when we introduce the bubble into the model. As the collateral value of the firm is now the going-concern, rather than the gone-concern value, it can include a bubble component (reflecting, for example, optimistic believes about the firm's future prospects). This means that a bubble can relax the collateral constraint by supporting higher equity values, which in turn allows the bubble to exist in equilibrium. Importantly, while Miao and Wang (2018) assume the collateral constraint is always binding, we allow it to bind only at times.

Competitive equilibrium. The competitive equilibrium of the economy is defined as follows.

Definition. For given initial values $k_{0}, L_{0}$ and an exogenous process $\left\{z_{t}, m_{t}\right\}_{t=0}^{\infty}$, a competitive equilibrium for the economy with bubble on the productive asset and a collateral constraint is a sequence of allocations $\left\{c_{t}, l_{t}, l_{t}^{d}, v_{t}, y_{t}, B_{t}\right\}_{t=0}^{\infty}$, an asset profile $\left\{k_{t+1}, L_{t+1}\right\}_{t=0}^{\infty}$, and a price system $\left\{q_{t}, p^{v}, R\right\}_{t=0}^{\infty}$, such that

1. Given the price system $\left\{q_{t}, p^{v}, R\right\}_{t=0}^{\infty}$, the allocations and the asset profile solve the households' and firms' problems,

2. The markets for labor, capital, and equity clear, $l_{t}^{d}=l_{t}, k_{t}=K_{t}=$ $1, \int_{j} \eta_{t}^{j} d j=1$, and

3. The resource constraint holds, $c_{t}+L_{t}=\frac{L_{t+1}}{R}+z_{t} F\left(1, l_{t}, v_{t}\right)-p^{v} v_{t}$.

Asset price bubble. To solve the firm's dynamic programming problem (7) subject to (8) and (9), we use the method of undetermined coefficients, and guess that the value function the firm maximizes takes the following form

$$
V\left(k_{t}, L_{t}\right)=a_{t} k_{t}+s_{t} L_{t}+b_{t}
$$

where $a_{t}$ and $s_{t}$ are coefficients associated with the fundamentals of the model. Following Miao and Wang (2018), the third component in the value function, $b_{t}$, is not related to the firm's fundamentals and is interpreted as a bubble component. Since the firm value is always non-negative, the bubble component must be greater or equal to zero.

In the Appendix A.2 we verify that the firm's value takes the following linear form after solving for $a_{t}$ and $s_{t}$ and substituting them back into the guessed value function 10

$$
V_{t}\left(k_{t}, L_{t}\right)=\left[R_{t}^{k}+q_{t}\left(1+m \mu_{t}\right)\right] k_{t}-L_{t}+b_{t}
$$


Here $R_{t}^{k}$ is the marginal product of capital and $\mu_{t}$ stands for the Lagrange multiplier corresponding to the collateral constraint (9). If $b_{t}=0$, the firm's value is equal to the fundamental value, while a positive $b_{t}$ lifts the market value of the firm and, via the collateral constraint, increases the firm's borrowing capacity. This can easily be seen by substituting the conjecture (11) into the collateral constraint (see Appendix A.2 for step-by-step derivations)

$$
\frac{L_{t+1}}{R}+\theta p^{v} v_{t} \leq m_{t}\left[q_{t} k_{t}+\beta E_{t}\left(\frac{U_{c, t+1}}{U_{c, t}} b_{t+1}\right)\right]
$$

The collateral constraint (12) depends on the capital stock at $t$, but also on the expected discounted size of the bubble component at $t+1$. It follows that the borrowing capacity of the firm increases with the expected rate of the bubble growth between $t$ and $t+1$.

The following proposition outlines the representative firm's optimality conditions; the proof is relagated to the Appendix A.3.

Proposition 1. In presence of a bubble $b_{t}$, the representative firm chooses $k_{t+1}, L_{t+1}, l_{t}^{d}, v_{t}$ in order to maximize its objective function (11) subject to the budget constraint (8) and the collateral constraint (12). In equilibrium the following optimality conditions are satisfied

1. Euler equation with respect to borrowing

$$
1=\beta E_{t} \frac{U_{c, t+1}}{U_{c, t}} R+\mu_{t}
$$

2. Euler equation with respect to capital

$$
U_{c, t} q_{t}=\beta E_{t}\left\{U_{c, t+1}\left[z_{t+1} F_{k, t+1}+q_{t+1}\left(1+m_{t+1} \mu_{t+1}\right)\right]\right\}
$$

3. Labor optimality condition

$$
w_{t}=z_{t} F_{l, t}
$$

4. Intermediate good optimality condition

$$
p^{v}\left(1+\theta \mu_{t}\right)=z_{t} F_{v, t},
$$


5. Complementarity slackness condition

$$
\mu_{t}\left[m_{t}\left(q_{t} k_{t}+B_{t}\right)-\frac{L_{t+1}}{R}-\theta p^{v} v_{t}\right]=0,
$$

where

$$
B_{t} \equiv \beta E_{t}\left(\frac{U_{c, t+1}}{U_{c, t}} b_{t+1}\right)
$$

6. Bubble accumulation process

$$
B_{t}=\beta E_{t}\left[\frac{U_{c, t+1}}{U_{c, t}}\left(1+m_{t+1} \mu_{t+1}\right) B_{t+1}\right]
$$

7. The cash flow constraint (8).

The presence of the collateral constraint of the form (12) distorts both the optimal inter- and intra-temporal margins when binding. Condition (16), defining the choice for the intermediate good, embeds an additional cost, i.e. the cost of collateral financing equal to $\theta \mu_{t} p_{v}$. In addition, both Euler equations are distorted. The Euler equation for borrowing (13) implies that the marginal benefit from increasing borrowing today outweighs the expected future marginal cost by an amount equal to the shadow price of relaxing the collateral constraint. Similarly, the Euler equation with respect to capital (14), equating the marginal cost of an extra unit of capital with its marginal benefit, embeds an additional benefit that derives from relaxing the collateral constraint, valued at $m_{t+1} \mu_{t+1} q_{t+1}$. As pointed out in Bianchi-Mendoza, this equation is at the core of the mechanism through which the pecuniary externalities operates: The choice of borrowing and consumption today influence the fundamental price of the asset $q$, which in turn affects the tightness of the collateral constraint.

However, in the presence of the bubble given by (19) firms' borrowing choices (which translate into consumption choices of the households) affect also the growth rate of the bubble. In particular, increasing current consumption (by increasing borrowing) results in lower marginal utility of consumption, which through equation (19) inflates the bubble. A larger bubble translates into higher stock market valuations that help relax the collateral constraint. As a result, the bubble increases the firm's borrowing capacity and dividend payouts to the households. This mechanism will be at the core of our policy analysis in Section 3 . 
Discussion of modeling assumptions. There are a few issues related to the way we model the asset price bubble that require a discussion. The first one is the assumption of market segmentation that allows the market value of the firm to differ from the fundamental value. This assumption is a common way to introduce bubbles on productive assets (see e.g. Miao, Wang and Xu (2015), Miao and Wang (2018), Martin, Moral-Benito and Schmitz (2018), Hirano and Yanagawa (2017)). Second, compared to Miao and Wang (2018), we do not study all possible equilibria ( $b_{t}=0$ being one) but focus on the case when the bubble has a positive value at some point in time. What matters for our policy analysis in Section 3 is that the value of the bubble is endogenous, giving rise to inefficiency in the presence of pecuniary externalities.

Finally, equation (19) shows that the bubble grows at a rate that is lower than the stochastic discount factor $\beta E_{t} \frac{U_{c, t+1}}{U_{c, t}}$, thanks to the liquidity premium $\left(E_{t} m_{t+1} \mu_{t+1}\right)$. This is due to the presence of the collateral constraint, which is binding in expectations. Importantly, the positive liquidity premium implies that the stock price bubble cannot be excluded by the transversality condition (6).

\section{Optimal macroprudential policy}

In the design of optimal policy, we proceed by first formulating the planner's problem and then discussing the properties of the optimal taxation.

\subsection{Time-consistent planner's problem}

The policy design follows the Ramsey approach, which consists in the social planner choosing policies, prices, and allocations in order to maximize the economy's social welfare function. In doing so, the planner has to respect all competitive economy equilibrium conditions to ensure that the allocations chosen can be implemented as allocations in the competitive economy.

Unlike in the standard Ramsey literature, where the planner optimally chooses distortionary policies intended to finance government expenditure, the planner here chooses policy to alleviate the inefficiencies arising from pecuniary externalities arising from occasionally binding collateral constraints. In particular, as in Bianchi-Mendoza, we assume that the only policy available to the planner is a tax on borrowing, $\tau{ }^{6}$ The tax is on new debt taken at period $t$, that needs to

\footnotetext{
${ }^{6}$ Alternative instruments that affect the intertemporal margin can be used instead.
} 
be repaid at time $t+1.7$ This instrument is Pigouvian in nature; therefore the tax revenues are rebated lump-sum back to the private agents, $T_{t} 8$ The private agents' Euler equation with respect to borrowing $(13)$ then takes the form

$$
U_{c, t}=\beta R\left(1+\tau_{t}\right) E_{t} U_{c, t+1}+\mu_{t}
$$

For simplicity of presentation, in the formulation of the Ramsey problem, we use a reduced set of competitive equilibrium conditions as constraints in the maximization problem. In the section A.4 in the Appendix we show that the planner's allocations obtained with this "relaxed" planner's problem, i.e. the one excluding conditions (15), (16), and (20) as constraints, yields the same allocations as those obtained with the "fully" constrained planner, i.e. the one that incorporates all equilibrium conditions as constraints in the planner maximization problem.

The set of competitive equilibrium equations faced by the planner comprises of (i) the resource constraint, (ii) the collateral constraint, (iii) the Euler equation with respect to capital. The inclusion of the last constraint reflects the fact that the planner has to respect competitive asset pricing in the economy. Through this equation, the planner how private agents' choices affect equilibrium asset pricing. In the presence of an asset price bubble, the set of constraints (i)-(iii), is expanded by an additional constraint, the bubble accumulation equation (19). Hence, the planner not only internalizes how private agents' decisions affect the equilibrium price of capital $q$, but also how they impact evolution of the bubbly component $B$ over time.

Finally, following Bianchi-Mendoza, we assume that the planner does not have the technology to commit to future policies. Therefore, it solves for the optimal time-consistent macroprudential policy, taking into account the effects of its optimal plans on future regulators' plans. As a result, the planner does not have incentives to deviate from policy rules of previous social planners. The planner's maximization problem is given by

\footnotetext{
${ }^{7}$ The tax on debt can also be imposed on the income generated by borrowing.

${ }^{8}$ The budget constraint of the decentralized economy then takes the following form: $c_{t}+L_{t}\left(1+\tau_{t-1}\right)+p^{v} v_{t} \leq \frac{L_{t+1}}{R}+z_{t} F(\cdot)+T_{t}$, where $T_{t}=-\frac{\tau_{t} L_{t+1}}{\left(1+\tau_{t}\right) R}$.
} 


$$
\begin{aligned}
& \max _{c_{t}, q_{t}, l, v_{t}, L_{t+1}, B_{t+1}} \sum_{t=0}^{\infty} \beta^{t} U\left(c_{t}, l_{t}\right) \\
& s . t \quad c_{t}+L_{t}+p^{v} v_{t} \leq z_{t} F\left(1, v_{t}, l\right)+\frac{L_{t+1}}{R} \quad\left(\lambda_{t}^{p}\right) \\
& \frac{L_{t+1}}{R}+\theta p^{v} v_{t} \leq m_{t}\left(q_{t}+B_{t}\right) \quad\left(\mu_{t}^{p}\right) \\
& q_{t} U_{c, t}=\beta E_{t} U_{c, t+1}\left[\left(q_{t+1}+F_{k, t+1}\right)+m_{t+1} \mu_{t+1} q_{t+1}\right] \\
& B_{t}=\beta E_{t} \frac{U_{c, t+1}}{U_{c, t}}\left(1+m_{t+1} \mu_{t+1}\right) B_{t+1}, \quad\left(\psi_{t}\right)
\end{aligned}
$$

where the Lagrange multipliers associated with each constraint are given in parenthesis. In sum, compared to the competitive economy, the planner's problem includes two additional constraints $(24)-(25)$.

The social planner's optimality conditions, after a few algebraic manipulations, take the following form

$$
\begin{gathered}
c:: \quad \lambda_{t}^{p}=U_{c, t}-\xi_{t} q_{t} U_{c c, t}-\psi_{t} E_{t} \frac{U_{c, t+1}}{U_{c, t}}\left(1+m_{t+1} \mu_{t+1}\right) B_{t+1} \frac{U_{c c, t}}{U_{c, t}} \\
q:: \quad \xi_{t} U_{c, t}=m_{t} \mu_{t}^{p} \\
B:: \quad m_{t} \mu_{t}^{p}=\psi_{t} \\
L:: \quad \lambda_{t}^{p}=\beta R E_{t} \lambda_{t+1}+\xi_{t} \Omega_{t+1}+\psi_{t} \Delta_{t+1} \mu_{t}^{p} \\
l:: \quad U_{c, t} G_{l, t}=-\lambda_{t}^{p} F_{l, t} \\
v:: \quad \mu_{t}^{p}=\frac{\lambda_{t}^{p}\left(F_{v, t}-p^{v}\right)}{\theta p^{v}}
\end{gathered}
$$

where $\Omega_{t+1}$ and $\Delta_{t+1}$ collect all partial derivatives with respect to $L_{t+1}$ on the righthand side of the capital-Euler and the bubble accumulation equations, capturing the impact of planner's choice of $L_{t+1}$ on the actions of future planners (reflecting the "time-consistency" nature of the policy rule). 
In analyzing the $\mathrm{CE}$ and planner's equilibrium allocations, we begin by comparing the CE's first order condition with respect to consumption, $\lambda_{t}=U_{c, t}$ to those of the Ramsey planner's in presence and in absence of a bubble..$^{9}$ Without an asset price bubble, i.e. when $B_{t}=0 \forall t$, the first order condition with respect to consumption of the planner is given by

$$
\lambda_{t}^{p}=U_{c, t}-\xi_{t} q_{t} U_{c c, t}
$$

In this case, the key difference between the $\mathrm{CE}$ and the Ramsey planner is that the latter's shadow value of wealth, in addition to the marginal utility of current consumption, also entails the amount by which an additional unit of consumption reduces marginal utility and relaxes the collateral constraint $\left(-\xi_{t} q_{t} U_{c c, t}\right)$.

When a bubble is present, the first order condition (32) is augmented by an additional term, Bubble $e_{t} \equiv-\psi_{t} E_{t} \frac{U_{c, t+1}}{U_{c, t}}\left(1+m_{t+1} \mu_{t+1}\right) B_{t+1} \frac{U_{c c, t}}{U_{c, t}}$, which is positive since $U_{c c, t}<0$. This term captures the amount by which an increase in $c_{t}$ reduces today's marginal utility of consumption, increases the discounted value of the bubble (see equation (25)), and relaxes the collateral constraint. Finally, if the collateral constraint does not bind at $t$, then $\mu_{t}^{p}=\xi_{t}=\psi_{t}=0$.

Next, we compare the CE's Euler condition with respect to borrowing (13) to the corresponding planner's condition. After substituting equation (26) in (29), the planner's Euler condition with respect to borrowing takes the following form

$U_{c, t}-\xi_{t} q_{t} U_{c c, t}+$ Bubble $_{t}=\beta R E_{t}\left\{U_{c, t+1}-\xi_{t+1} q_{t+1} U_{c c, t+1}+\right.$ Bubble $\left._{t+1}+\xi_{t} \Omega_{t+1}+\psi_{t} \Delta_{t+1}\right\}+\mu_{t}^{p}$.

The best way to do the comparison is to highlight the pecuniary externalities operating through the current and the future price of capital and the bubble component of the firm's value in two cases: when the collateral constraint binds and when it does not.

1. The collateral constraint does not bind at $t$, but may bind at $t+1$ : effects via $q_{t+1}$ and $B_{t+1}$. First, without an asset price bubble $\left(B_{t} \forall t\right)$, when $\mu_{t}=0$, the marginal cost of borrowing at $t$ is higher for the social planner than for the private agents by an amount $\xi_{t+1} U_{c c, t+1} q_{t+1}$. This term reflects the fact that the planner internalizes the effect of a larger debt at $t$ on reducing the borrowing capacity at $t+1$ through a lower price of capital, $q_{t+1}$, if the constraint binds at $t+1$. As pointed out in Bianchi-Mendoza, this mechanism operates through equation (24):

\footnotetext{
${ }^{9}$ The no-bubble scenario simply replicates the analytical results in Bianchi-Mendoza.
} 
A binding collateral constraint at $t+1$ would result in lower consumption, higher marginal utility, and hence a lower future price of fundamental capital $q_{t+1}$.

When an asset price bubble is present, the marginal cost of borrowing at $t$ is higher by an additional amount Bubble $_{t+1}$. This term is at the core of our optimal policy analysis and captures the impact of current borrowing on the future size of the bubble, conditional on the bubble not bursting between $t$ and $t+1$. The mechanism operate through equation (25): As more borrowing today implies a larger reduction in consumption tomorrow in the states when the collateral constraint binds, this will also deflate the bubble, which grows with consumption. As elevated asset prices help alleviate adverse welfare effects when collateral constraints binding, the planner tries to avoid deflating bubbles exactly when borrowing capacity is curtailed. Hence, the planner can do so by leaning against debt build-up more aggressively ex-ante.

2. The collateral constraint binds at $t$ and may bind at $t+1$ : effects via $q_{t}$, $q_{t+1}$ and $B_{t}, B_{t+1}$. In the event when the collateral constraint binds at $t$ and may also bind at $t+1$, there are two opposing effects resulting from the borrowing decision that the planner takes into account. In particular, the planner faces a tradeoff between choosing allocations such that it increases $q_{t}$ at the cost of potentially decreasing $q_{t+1}$. This tradeoff occurs regardless of whether there is a bubble or not. The mechanism operates as follows: More borrowing, accompanied by higher consumption at $t$, increases the price of capital $q_{t}$ and relaxes the collateral constraint. At the same time, more borrowing and higher consumption at $t$ may result in lower consumption and lower price of capital at $t+1$ in the event the collateral constraint continues to bind. Similar is the effect through $B_{t}$ and $B_{t+1}$. Hence, the impact of the borrowing decision on the asset price and the bubble is ambiguous when the collateral constraint binds at $t$ and may bind at $t+1$ : The planner chooses allocations such that it balances between increasing current prices and inflating bubbles, and the cost of the possibility of decreasing future prices and deflating bubbles.

\subsection{Optimal tax rate in the presence of a bubble}

The optimal tax on debt can be derived by comparing the borrowing Euler equation of the Ramsey planner (33) with the corresponding equation of the agents incorporating the tax on borrowing 20 . 
Proposition 2. The optimal tax on debt responds to asset price bubbles beyond its role in tackling overborrowing and is given by

$$
\begin{aligned}
1+\tau_{t} & =\frac{E_{t}\left[U_{c, t+1}-\xi_{t+1} q_{t+1} U_{c c, t+1}-\xi_{t} \Omega_{t+1}\right]}{E_{t} U_{c, t+1}}+\frac{\xi_{t} q_{t} U_{c c, t}}{\beta R E_{t} U_{c, t+1}} \\
& +\frac{E_{t} B u b b l e_{t+1} \Delta_{t+1}}{E_{t} U_{c, t+1}}-\frac{\text { Bubble }_{t}}{\beta R E_{t} U_{c, t+1}} .
\end{aligned}
$$

Proposition 2 states that the optimal tax rate, in addition to tackling credit growth, will also affect the size of the asset bubble. In particular, the first line of equation (34) is equal to the Bianchi-Mendoza tax rate, whereas the second line contains the additional terms that arise because of the presence of the bubble in the economy. In general, the tax rate continues to have two components that match the $q_{t}$ and $q_{t+1}$ effects on the social marginal benefit of savings identified earlier, however both of them are augmented by the additional terms $B_{t}$ and $B_{t+1}$ generated by the presence of the bubble.

Similar to Bianchi-Mendoza, we can define the macroprudential component on the tax on borrowing, which collects the terms from the tax rate that are present when the collateral constraint does not bind at $t\left(\mu_{t}=0\right)$, but may bind at $t+1\left(E_{t} \mu_{t+1}\right)$. In particular, the first component in the first line in the tax rate (34) matches the pecuniary externality operating via $q_{t+1}$, identified in Bianchi-Mendoza. Moreover, the first component in the second line in equation (34) matches the pecuniary externality operating via $B_{t+1}$, which represents the novel, additional component arising from the presence of the bubble. Denoting these two components by $\tau_{t}^{m p}$, the macroprudential tax on debt, we can state the following.

Lemma 3. In presence of an asset price bubble, the macroprudential tax on debt levied, when credit is not constrained today but it may be constrained tomorrow, is higher when price overvaluations are present:

$$
\tau_{t}^{b}=-\frac{E_{t}\left[\xi_{t+1} q_{t+1} U_{c c, t+1}-\text { Bubble }_{t+1}\right]}{E_{t} U_{c, t+1}} .
$$

Suppose the bubble has bursted at $t$. Then, the macroprudential tax on debt would be given by $\tau_{t}^{n b}=-\frac{E_{t}\left[\xi_{t+1} q_{t+1} U_{c, t+1}\right]}{E_{t} U_{c, t+1}}$, which is positive, and exactly replicates the Bianchi-Mendoza tax rate. Intuitively, it aims to hamper credit growth in good times in order to lower the risk of future instability when the collateral constraint becomes binding.

Suppose the bubble has not bursted at $t$ and it continues to exist at $t+1$. Then, 
the macroprudential tax is amplified by an additional term Bubble $_{t+1}$, which as shown before is positive. Its goal is to limit the downward pressures a deflating bubble can have on asset prices in the states when the collateral constraint binds in the future. In other words, for the same level of credit imbalances, the planner should lean against credit growth more aggressively if asset prices are elevated as well. We will refer to this contribution to the macroprudential tax as the intensive margin.

However, the mere presence of a bubble can also make the collateral constraint at times slack: Higher asset prices increase the value of the collateral, thereby relaxing the constraint and increasing the borrowing capacity. As a result, the probability of the collateral constraint binding in the future and the equilibrium allocations change. We will refer to this contribution to the macroprudential tax as the extensive margin.

The intensive and the extensive margins can be isolated by computing the difference between the macroprudential tax with (equation 35) and without a bubble (Bianchi-Mendoza macroprudential tax rate). The overall impact of the bubble on the level of the macroprudential tax is given by

$$
\tau_{t}^{b}-\tau_{t}^{n b}=\underbrace{-\Delta \frac{E_{t}\left[\xi_{t+1} q_{t+1} U_{c c, t+1}\right]}{E_{t} U_{c, t+1}}}_{\text {Extensive margin }}+\underbrace{\frac{E_{t} B u b b l e_{t+1}}{E_{t} U_{c, t+1}}}_{\text {Intensive margin }} .
$$

Since the sign of the differential tax rate is ambiguous, to verify which of the two effects - intensive vs. extensive margin - prevails and under which conditions, in the next section we solve the model numerically and show that the relative strength of the two margins depends on the current debt level $L_{t}$, which highlights the non-linear dependance of the macroprudential tax on bubbles.

\section{Quantitative analysis}

In this section we present the quantitative predictions of the model. We proceed by first briefly discussing the baseline calibration, and then turn to the numerical result. In what follows, we consider a stochastic bubble, i.e. we allow the bubble to pop with exogenous probability $\pi$ (see Blanchard and Watson (1982) and Weil (1987) for stochastic bubbles as well as Miao and Wang (2018) for a full derivation of equilibrium with a stochastic bubble). 


\subsection{Calibration}

We calibrate most of the the parameters following Bianchi-Mendoza, to allow for close comparisons of our results-in a model with a bubble-with their bubbleless economy. Thus, for calibration details of all non-bubble parameters we refer the reader to their Section III.A. One exception is the global interest rate $R$, which in Bianchi-Mendoza follows an $\mathrm{AR}(1)$ process. In our case, in oder to limit the number of states for the numerical solution, we keep $R$ fixed at its long-term average level, calibrated to $\bar{R}=1.01$.

The parameters associated with the asset price bubble are calibrated to the results of Jordà, Schularick and Taylor (2015), who study bubbles in housing and equity markets in 17 countries over the past 140 years. They report summary statistics separately for house and for equity bubbles, in pre- and post-World War II periods (see Table 2 in their paper). As Bianchi-Mendoza do not distinguish between housing versus other types of assets, we calibrate the bubble parameter $\pi$ to the average duration of the two types of bubbles, weighted by their relative frequency, all reported in Jordà, Schularick and Taylor (2015). Given the sample period used for calibrating other model parameters, we focus on the post-World War II bubbles. The average duration of a bubble in this period was 2.3 years, which implies a survival probability of $\pi=0.56$ in our model. For a period of price growth to be identified as a bubble, Jordà, Schularick and Taylor (2015) require that $\log$ real asset prices diverge significantly from their trend, becoming elevated by more than one standard deviation from a country-specific Hodrick-Prescott filtered trend ( $\lambda=100$, annual data). This implies an average deviation of real asset prices from their long-term trend of around 8 percent in the first year of the bubble. In the numerical algorithm, we take the size of the bubble in the current period as given and calibrate it so that it is equal to 8 percent of the price $q_{t}$ on average.

Table 1 summarizes all parameter values. The functional forms for preferences and technology are:

$$
\begin{aligned}
& U=\frac{\left(c-\chi \frac{l^{1+\omega}}{1+\omega}\right)^{1-\sigma}-1}{1-\sigma}, \quad \omega, \chi>0, \sigma>1 \\
& F=e^{z} k^{\alpha_{k}} v^{\alpha_{v}} l^{\alpha_{l}}, \quad \alpha_{k}, \alpha_{v}, \alpha_{l} \leq 1
\end{aligned}
$$

Total factor productivity (TFP) follows an independent AR(1) process, given by:

$$
z_{t}=\bar{z}+\rho_{z} z_{t-1}+\epsilon_{t}, \quad \epsilon_{t} \sim N\left(0, \sigma_{\epsilon}\right)
$$


The productivity shock is discretized using the Tauchen's quadrature method with three realizations $z^{l}, \bar{z}, z^{h}$, with $z^{l}<\bar{z}<z^{h}$. The parameter in the collateral constraint, $m_{t}$, follows a two-state regime switching Markov process with two states $\left\{m^{l}, m^{h}\right\}$, where $m^{l}$ denotes tight and $m^{h}$ denotes normal credit conditions, respectively. This process is also assumed to be independent from the Markov process for $z$. Finally, $P_{x, y}$ in Table 1 denote the transition probabilities from a state $x$ to a state $y$.

Table 1: Calibration.

Parameters

Risk aversion

Share of intermediate good in output

Share of labor in output

Share of assets in output

Labor disutility coefficient

Fischer elasticity

Working capital coefficient

Tight credit regime

Normal credit regime

Global interest rate

TFP process

Value

Discount factor

Transition probability, $m^{h}$ to $m^{l}$ $\sigma=1$

$\alpha_{v}=0.45$

$\alpha_{l}=0.352$

$\alpha_{k}=0.008$

$\chi=0.352$

$1 / \omega=2$

$\theta=0.16$

$m^{l}=0.75$

$m^{h}=0.90$

$R=1.01$

$\rho_{z}=0.78$

$\sigma_{\epsilon}=0.01$

$\beta=0.95$

Transition probability, $m^{l}$ to $m^{l}$

$P_{h, l}=0.1$

$P_{l, l}=0$

Bubble bursting probability

$\pi=0.56$

Bubble size at period $t$ (in percent of the price of capital)

\subsection{Numerical results}

To solve the model, we use a global, nonlinear solution algorithm. The CE solution is obtained using first-order conditions, and to solve the SP problem, we apply a value function iteration algorithm. Both methods are augmented to incorporate the occasionally-binding collateral constraint (see Appendix A.5 for details).

Graphical analysis of optimal policy. To better understand the difference between optimal policy in the presence and in the absence of an asset price bubble, it is useful to start with a graphical depiction of the financial amplification mechanism due to pecuniarity externalities in the absence of a bubble. Figure 2 plots new borrowing $\left(L_{t+1}\right)$ policy rules for the CE and the SP in two consecutive 
periods. 10

Suppose that the first period firms in the CE start with outstanding debt $L_{1}$, for which the optimal new borrowing (solid lines) is the same as in period zero $\left(L_{2}^{C E}=L_{1}\right)$, corresponding to point $C E_{1}$ in Figure 2. Instead, for the same value of $L_{1}$, the SP chooses to borrow much less $\left(L_{2}^{S P}\right)$, ending up at the point $S P_{1}$. Now suppose that in the second period a negative collateral constraint shock hits, i.e. $m_{2}=m^{l}$. The collateral constraint becomes binding for firms in the CE, triggering deflation of asset prices and forcing firms to considerably reduce the new borrowing (dashed lines) to $L_{3}^{C E}$. In comparison, a much lower starting level of outstanding debt in the second period $\left(L_{2}^{S P}<L_{2}^{C E}\right)$ allows the SP to keep new borrowing at a similar level as before $\left(L_{3}^{S P}\right)$. As a result, the SP achieves much smaller fluctuations of debt and lower frequency of financial crisis.

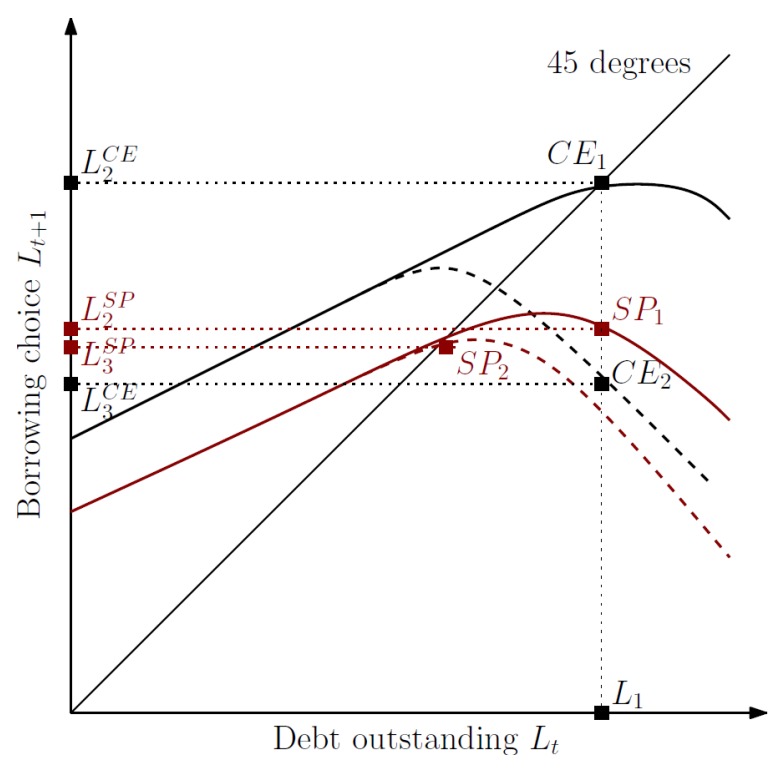

Figure 2: Responses to a collateral shock: SP versus CE.

The figure plots the new borrowing policy rules for the CE (black lines) and the SP (dark red lines) in two periods: period 1 (solid lines) when the collateral constraint parameter is equal $m_{1}=m^{h}$, and period 2 (dashed lines) when a negative collateral constraint shock hits, i.e. $m_{2}=m^{l}$.

Policy functions and optimal macroprudential tax in the presence of asset price bubbles. We now move to the analysis of the numerical results and discussion of optimal policy rules in the presence of asset price bubbles. Figure 3 shows new borrowing $L_{t+1}$ and the price $q_{t}$, as functions of the outstanding debt level, $L_{t}$, when collateral regime is high and productivity is low $\left(m_{t}=m^{h}\right.$

\footnotetext{
${ }^{10}$ We follow a similar exercise performed by Bianchi-Mendoza (see their Figure 3).
} 
and $z_{t}=z^{l}$ ). Top panels show the case when there is no bubble, and bottom panels-when there is a bubble. The red (blue) vertical lines mark outstanding debt levels above which the collateral constraint binds today in the CE (in the SP equilibrium).

First, note that the SP chooses new borrowing $L_{t+1}$ always lower than in the competitive equilibrium, independently of bubble's presence. It does so to internalize pecuniary externalities and mitigate their negative impact on consumption and welfare. The price of capital is lower under the SP than in the CE: For the assumed parameter values, the first-order effect of the SP's debt tax - which through arbitrage of returns between assets and bonds raises the expected return on assets in SP equilibrium - outweighs the effect that higher risk premia have for pushing asset prices down in the CE. In general, it is possible to obtain a higher price of capital $q_{t}$ in the SP equilibrium than in the CE for alternative calibration choices.

Consistent with that, the collateral constraint starts binding in the SP equilibrium for much lower levels of debt that in the CE. This happens as lower SP borrowing, $L_{t+1}$, puts a downward pressure on prices, tightening the borrowing constraint further. 

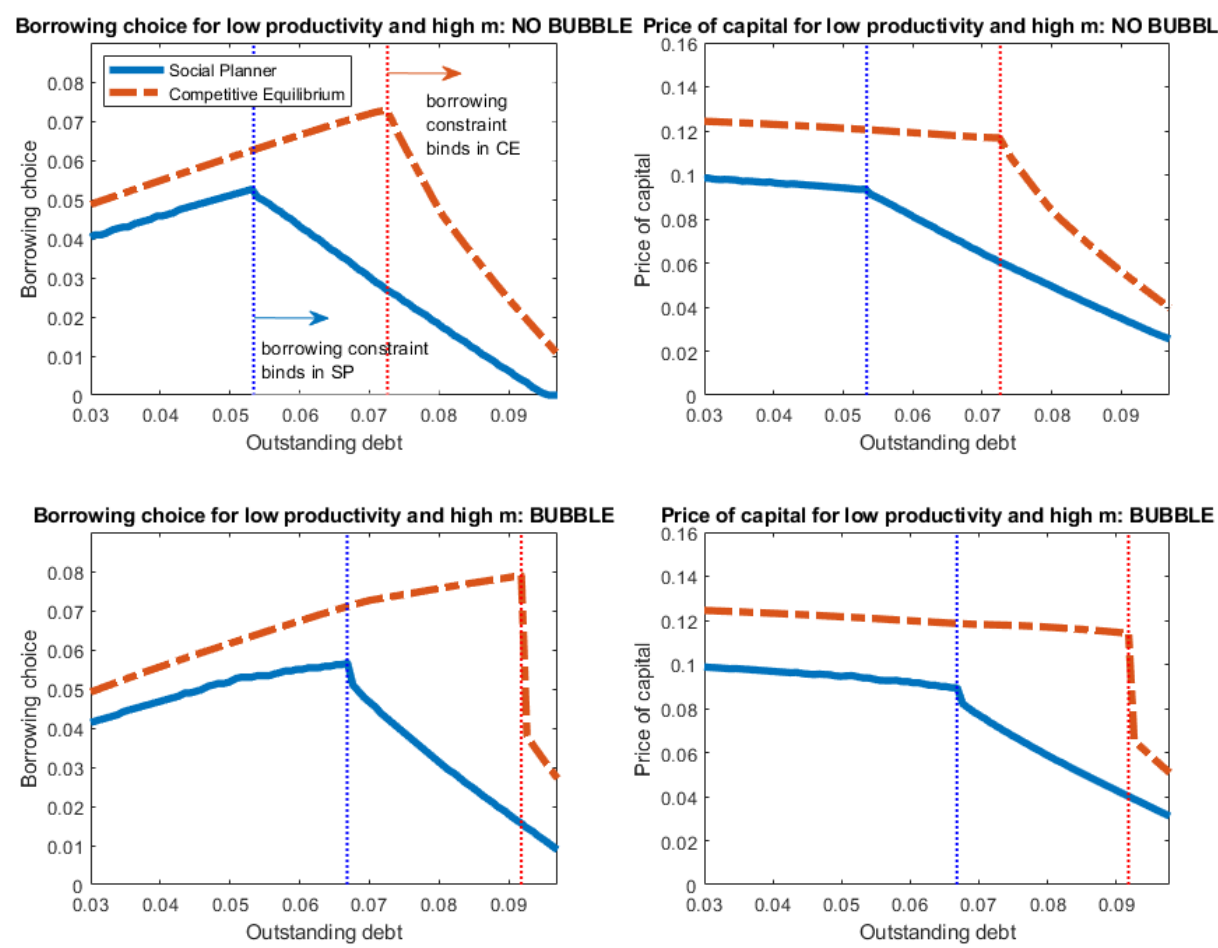

Figure 3: New borrowing and price of capital: Policy rules in the presence of an asset price bubble.

The figure plots the new borrowing $L_{t+1}$ (panels on the left) and price of capital $q_{t}$ (panels on the right) as a function of outstanding debt $L_{t}$, for $z_{t}=z^{l}$ and $m_{t}=m^{h}$. Top panels show a model without a bubble, and bottom panels correspond to the model with an asset price bubble. The blue lines correspond to the SP policy rules, while the red dashed lines represent the CE case. The collateral constraint binds for outstanding debt levels to the right from the red (CE) and blue (SP) vertical lines.

There are noteworthy differences between the model with and without a bubble. First, the bubble has a positive effect on relaxing the collateral constraint and thus removing the financial friction for moderate levels of debt outstanding. Because the value of the firm is now higher than before, the bubble allows to sustain a higher threshold of $L_{t}$, above which the constraint starts binding, both in the $\mathrm{CE}$ and in the SP equilibrium (the vertical lines in Figure 3 move further to the right). In the region where the constraint binds in the absence of the bubble, but does not when the bubble is present, the bubble allows to sustain a higher price of capital $q_{t}$, reflecting higher purchases of capital and a lower probability of the constraint binding next period. 

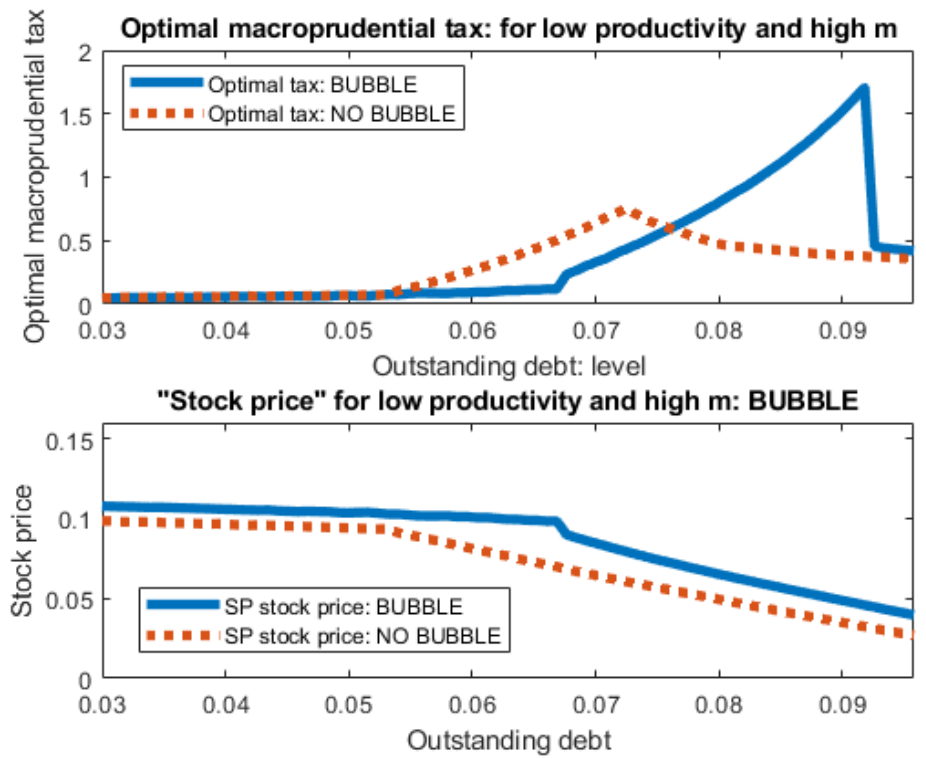

Figure 4: Optimal macroprudential tax in the presence of an asset price bubble.

The top panel plots the optimal tax in the absence (dotted red line) and in the presence of a bubble (solid blue line) as a function of debt outstanding, $L_{t}$. The bottom panel plots the price that enters the collateral constraint: $q_{t}+B_{t}$ in the same two cases.

Figure 4 plots the optimal macroprudential tax with a bubble (solid blue line) and without a bubble (red dotted line) as a function of outstanding debt $L_{t}$. For very low levels of debt the tax is close to zero, independently of whether there is a bubble or not. That is, for subdued levels of credit, there is no need for macroprudential intervention, irrespecitve of asset price pressures.

For low to medium levels of credit, the optimal tax is actually lower when the bubble is present: The extensive margin pushes the tax down and dominates the intensive margin. For moderate values of $L_{t}$, the bubble reduces the probability of the collateral constraint binding in the next period (as it lifts up the level of debt above which the constraint binds, see Figure 3), while the future negative externalities from the bubble deflating in an event of a binding collateral constraint are still modest (given moderate debt levels). This justifies lifting the tax "later", i.e. for higher levels of $L_{t}$ when the bubble is present.

On the contrary, for high levels of $L_{t}$ the tax rate is much higher in a bubbly economy. Under elevated credit conditions, the expected future costs of the bubble deflating when the collateral constraint binds dominate potential benefits and the intensive margin prevails over the extensive margin.

Finally, the optimal tax starts to decline (both with and without the bubble) once $L_{t}$ is so high that the collateral constraint binds today-consistent with the $\mathrm{SP}$ weighting the costs of the constraint binding in the future with the benefits of 
relaxing it today.

In sum, our results suggest that asset price overvaluations might not be enough by themselves to justify a tightening of macroprudential policy. This happens as for low or moderate levels of credit, the bubble's persistence into the next periods makes tight financial conditions less likely in the future, while the costs of it deflating in the future are still low. As a result, under our calibration choices, it is optimal not to lean against the bubble when credit is low.

\section{Conclusions}

We study optimal macroprudential policy when credit growth is accompanied by asset price bubbles. To this end, we augment the model of Miao and Wang (2018), which features rational stock price bubbles, with occasionally binding collateral constraint akin to Bianchi and Mendoza (2018). Our analytical results suggest that, for the same levels of credit imbalances, macroprudential policy should respond more aggressively when asset prices are overvalued in order to avoid a bubble deflation in bad times when its collateral value is useful to relax credit constraints. As the presence of the bubble alters equilibrium allocations, the overall response of a macroprudential tax on borrowing to growing asset price overvaluations might be either positive or negative. Our numerical results suggest that the response depends on the current level of borrowing in the economy in a non-linear way. Importantly, when the credit imbalances are high, the optimal tax level is higher than in the absence of bubbles. 


\section{REFERENCES}

Adrian, Tobias and Hyun Song Shin (2009), 'Money, liquidity, and monetary policy', American Economic Review: Papers $\&$ Proceedings 99(2), 600-605.

Aoki, Kasuke and Kalin Nikolov (2015), 'Bubbles, banks and financial stability', Journal of Monetary Economics 74, 33 - 51.

Barlevy, Gadi (2018), 'Bridging between policymakers' and economists' views on bubbles', Economic perspectives 42(4), 1-21.

Bengui, Julien and Toan Phan (2018), 'Asset pledgeability and endogenously leveraged bubbles', Journal of Economic Theory 177, 280 - 314.

Bernanke, Ben, Mark Gertler and Simon Gilchrist (1999), 'The financial accelerator in a quantitative business cycle framework', in Handbook of Macroeconomics. Volume 1C, ed. John B. Taylor and Michael Woodford pp. 1341-1393.

Bianchi, Javier (2011), 'Overborrowing and systemic externalities in the business cycle', American Economic Review 101(7), 3400-3426.

Bianchi, Javier and Enrique C. Mendoza (2018), 'Optimal time-consistent macroprudential policy', Journal of Political Economy 126(2), 588-634.

Blanchard, Oliver and Mark Watson (1982), 'Bubbles, rational expectations and financial markets. in: Wachtel, p., ed., crises in the economic and financial structure', Lexington Books pp. 295-315.

Caballero, Ricardo J. and Arvind Krishnamurthy (2006), 'Bubbles and capital flow volatility: Causes and risk management', Journal of Monetary Economics 53(1), 35-53.

Chauvin, Kyle, David Laibson and Johanna Mollerstrom (2011), 'Asset bubbles and the cost of economic fluctuations', Journal of Money, Credit, and Banking 43, 233-260.

Eggertsson, G.B. and P. Krugman (2012), 'Debt, deleveraging, and the liquidity trap: A Fisher-Minsky-Koo approach', The Quarterly Journal of Economics 127(3), 1469-1513.

Farhi, Emmanuel and Iván Werning (2016), 'A theory of macroprudential policies in the presence of nominal rigidities', Econometrica 84(5), 1645-1704. 
Farhi, Emmanuel and Jean Tirole (2012), 'Collective moral hazard, maturity mismatch, and systemic bailouts', American Economic Review 102(1), 60-93.

Fostel, Ana and John Geanakoplos (2008), 'Leverage cycles and the anxious economy', American Economic Review 98(4), 1211-1244.

Hirano, Tomohiro and Noriyuki Yanagawa (2017), 'Asset bubbles, endogenous growth, and financial frictions', The Review of Economic Studies 84(1), 406443.

Jeanne, Olivier and Anton Korinek (2010), 'Managing Credit Booms and Busts: A Pigouvian Taxation Approach', (WP10-12).

Jermann, Urban and Vincenzo Quadrini (2012), 'Macroeconomic effects of financial shocks', American Economic Review 102(1), 238-271.

Jordà, Òscar, Moritz Schularick and Alan M. Taylor (2015), 'Leveraged bubbles', Journal of Monetary Economics 76, S1-S20.

Kiyotaki, Nobuhiro and John Moore (1997), 'Credit cycles', Journal of Political Economy 105(2), 211-248.

Kiyotaki, Nobuhiro and John Moore (2012), 'Liquidity, business cycles and monetary policy', NBER Working Paper No. 17934.

Kocherlakota, Narayana R. (1992), 'Bubbles and constraints on debt accumulation', Journal of Economic Theory 57(1), 245 - 256.

Kocherlakota, Narayana R. (2008), 'Injecting rational bubbles', Journal of Economic Theory 142(1), $218-232$.

Korinek, Anton (2011), 'Systemic risk-taking: Amplifications effects, externalities and regulatory responses', ECB WP 1345.

Korinek, Anton and Alp Simsek (2016), 'Liquidity trap and excessive leverage', American Economic Review 106(3), 699-738.

Laeven, Luc and Fabian Valencia (2012), 'Systemic banking crises database: an update', IMF Working Paper 12/163.

Lorenzoni, G. (2008), 'Inefficient credit booms', Review of Economic Studies 75(3), 809-833. 
Martin, A., A. Moral-Benito and T. Schmitz (2018), The financial transmission of housing bubbles: Evidence from spain. CEPR Discussion Paper No. DP12999.

Martin, Alberto and Jaume Ventura (2012), 'Economic growth with bubbles', American Economic Review 102(6), 3033-58.

Miao, Jianjun and Pengfei Wang (2015), 'Banking bubbles and financial crises', Journal of Economic Theory 157, 763 - 792.

Miao, Jianjun and Pengfei Wang (2018), 'Asset bubbles and credit constraints', American Economic Review 108(9), 2590-2628.

Miao, Jianjun, Pengfei Wang and Jing Zhou (2015), 'Asset bubbles, collateral, and policy analysis', Journal of Monetary Economics 76, S57 - S70.

Miao, Jianjun, Pengfei Wang and Zhiwei Xu (2015), 'A bayesian dynamic stochastic general equilibrium model of stock market bubbles and business cycles', Quantitative Economics 6(3), 599-635.

Mishkin, Frederic S. (2011), 'Monetary Policy Strategy: Lessons from the Crisis', (16755).

Santos, Manuel S. and Michael Woodford (1997), 'Rational asset pricing bubbles', Econometrica 65(1), 19-58.

Scheinkman, José A. and Laurence Weiss (1986), 'Borrowing constraints and aggregate economic activity', Econometrica 54, 23-46.

Stein, J.C. (2012), 'Monetary policy as financial-stability regulation', The Quarterly Journal of Economics 127(1), 57-95.

Weil, Philippe (1987), 'Confidence and the real value of money in an overlapping generations economy', Quarterly Journal of Economics 102(1), 1-22. 


\section{A Appendix}

\section{A.1 Derivation of Collateral Constraint}

The collateral constrained (9) can be derived from a renegotiation of debt problem between borrowers and lenders. At the beginning of period $t$, after $b_{t}$ has been repaid, the total liabilities of the borrower (firm) equal to $\theta p^{v} v_{t}+\frac{L_{t+1}}{R}$. Before production and investment in new capital takes place, borrowers can decide to divert the borrowed funds. If the diversion does not take place at that specific point in time, there will be no opportunity for borrowers to divert within the same period. Using the threat to divert, borrowers can try to renegotiate their liabilities. If creditors do not agree to renegotiate the debt, they would seize the firm, which can then be sold at equity markets. The value of the seized firm is given by $m \beta E_{t} V_{t+1}\left(k_{t}, 0\right)$, where $m$ denotes the probability of a credible enforcement of seizing and reselling the firm in equity markets. Importantly, following Jermann and Quadrini (2012), we assume that the firm has full negotiation power.

Then, the value to the firm from renegotiating its debt is given by

$$
V^{R}=\theta p^{v} v_{t}+\frac{L_{t+1}}{R}-m_{t} \beta E_{t} \frac{U_{c, t+1}}{c_{t}} V_{t+1}\left(k_{t}, 0\right)+\beta E_{t} \frac{U_{c, t+1}}{c_{t}} V_{t+1}\left(k_{t+1}, L_{t+1}\right)
$$

The first three terms in the value function above denote the net renegotiated debt benefit; that is the total liabilities net of the firm's value after funds have been diverted.

The value to the firm from avoiding renegotiation is given by

$$
V^{N R}=\beta E_{t} \frac{U_{c, t+1}}{U_{c, t}} V_{t+1}\left(k_{t+1}, L_{t+1}\right) .
$$

The incentive compatibility constraint requires that the net renegotiation value is smaller or equal to the value from honoring the debt obligations, $V^{N R} \geq V^{R}$. This incentive compatibility constraint gives rise to the collateral constraint (9).

\section{A.2 Conjecture and Verify: Firm's Value Function}

Conjecture that the value function of the representative firm is given by $V_{t}\left(k_{t}, L_{t}\right)=$ $a_{t} k_{t}+s_{t} L_{t}+b_{t}$. Substituting this conjecture into the firm's optimization problem (7), and the constraints (8)-(9) yields:

$$
a_{t} k_{t}+s_{t} L_{t}+b_{t}=\max _{k_{t+1}, L_{t+1}, l_{t}, v_{t}} D_{t}+\beta E_{t}\left(\frac{U_{c, t+1}}{U_{c, t}}\left(a_{t+1} k_{t+1}+s_{t+1} L_{t+1}+b_{t+1}\right)\right),
$$


subject to

$$
D_{t}=F\left(k_{t}, l_{t}^{d}, v_{t}\right)-p^{v} v_{t}-w_{t} l_{t}^{d}+\frac{L_{t+1}}{R}-L_{t}+q_{t} k_{t}-q_{t} k_{t+1},
$$

and

$$
\frac{L_{t+1}}{R}+\theta p^{v} v_{t} \leq m_{t} \beta E_{t}\left(\frac{U_{c, t+1}}{U_{c, t}}\left(a_{t+1} k_{t}+b_{t+1}\right)\right) .
$$

Taking first-order conditions with respect to $k_{t+1}, L_{t+1}, l_{t}^{d}, p_{t}^{v}$ respectively yields:

$$
q_{t}=\beta E_{t}\left(\frac{U_{c, t+1}}{U_{c, t}} a_{t+1}\right)
$$

$$
\frac{1}{R_{t}}=\frac{\mu_{t}}{R}-\beta E_{t}\left(\frac{U_{c, t+1}}{U_{c, t}} s_{t+1}\right)
$$

$$
w_{t}=F_{l, t}
$$

$$
p^{v}=F_{v, t} \frac{1}{1+\theta \mu_{t}} .
$$

where $\mu_{t}$ is the Lagrange multiplier on the collateral constraint A.5. Substituting back into A.3 and simplifying yields

$$
\begin{aligned}
& a_{t} k_{t}+s_{t} L_{t}+b_{t}=F\left(k_{t}, l_{t}^{d}, v_{t}\right)-F_{l, t} l_{t}^{d}-F_{v, t} v_{t}-L_{t}+q_{t} k_{t} \\
+ & \mu_{t}\left[m_{t} \beta E_{t}\left(\frac{U_{c, t+1}}{U_{c, t}}\left(a_{t+1} k_{t}+b_{t+1}\right)\right)\right]+\beta E_{t}\left(\frac{U_{c, t+1}}{U_{c, t}} b_{t+1}\right)
\end{aligned}
$$

where we have used the complementary slackness condition,

$$
\mu_{t}\left[\theta p^{v} v_{t}+m_{t} \beta E_{t}\left(\frac{U_{c, t+1}}{U_{c, t}}\left(a_{t+1} k_{t}+b_{t+1}\right)\right)\right]=0,
$$

to substitute out the $\mu_{t} \frac{L_{t+1}}{R}$. Comparing LHS and RHS yields:

$$
\begin{gathered}
a_{t}=R_{t}^{k}+q_{t}\left(1+m_{t} \mu_{t}\right), \\
s_{t}=-1, \\
b_{t}=\left(1+m_{t} \mu_{t}\right) \beta E_{t}\left(\frac{U_{c, t+1}}{U_{c, t}} b_{t+1}\right),
\end{gathered}
$$


where $R_{t}^{k}=F\left(k_{t}, l_{t}^{d}, v_{t}\right)-F_{l, t} l_{t}^{d}-F_{v, t} v_{t}$. Thus, the value functions takes the form

$$
V_{t}\left(k_{t}, L_{t}\right)=\left(R_{t}^{k}+q_{t}\left(1+m_{t} \mu_{t}\right)\right) k_{t}-L_{t}+b_{t}
$$

Moreover, using the above to substitute out $a_{t+1}$ yields the credit constraint:

$$
\frac{L_{t+1}}{R}+\theta p^{v} v_{t} \leq m_{t}\left(q_{t} k_{t}+B_{t}\right)
$$

where

$$
B_{t} \equiv \beta E_{t}\left(\frac{U_{c, t+1}}{U_{c, t}} b_{t+1}\right)
$$

\section{A.3 Proof of Proposition 1}

Using that $a_{t+1}=R_{t+1}^{k}+q_{t+1}\left(1+m_{t+1} \mu_{t+1}\right)$ and $s_{t+1}=-1$, the first-order conditions A.6)-A.7 can be rewritten as

$$
\begin{gathered}
\mu_{t}=1-\beta R E_{t}\left(\frac{U_{c, t+1}}{U_{c, t}}\right), \\
U_{c, t} q_{t}=\beta E_{t}\left(U_{c, t+1} z_{t+1} F_{k, t+1}+q_{t+1}\left(1+m_{t+1} \mu_{t+1}\right)\right),
\end{gathered}
$$

yielding, together with equations (A.8)- A.9), the first-order conditions $130-(16)$ in Proposition 1. To derive the bubble accumulation process (19), we use the definition of $B$ in A.16), where

$$
b_{t}=\left(1+m_{t} \mu_{t}\right) \beta E_{t}\left(\frac{U_{c, t+1}}{U_{c, t}} b_{t+1}\right) .
$$

Iterating forward yields

$$
b_{t+1}=\left(1+m_{t+1} \mu_{t+1}\right) \beta E_{t+1}\left(\frac{U_{c, t+2}}{U_{c, t+1}} b_{t+2}\right)=\left(1+m_{t+1} \mu_{t+1}\right) B_{t+2} .
$$

Substituting out $b_{t+1}=\beta E_{t} B_{t+1} \frac{1}{\frac{U_{c, t+1}}{U_{c, t}}}$ gives $(19)$.

\section{A.4 Equivalence Between the "Relaxed" and "Fully" Con- strained Ramsey Problem}

Section 3.1 in the main text outlines the problem of the Ramsey planner, which consists of maximizing the welfare of the private agents subject to a subset of the competitive equilibrium optimality conditions. Here we show that the allocations obtained by the "relaxed" planner's optimization problem are equivalent to those obtained by a "fully" constrained planner, i.e. one that takes into account all competitive equilibrium conditions. 
We proceed by first providing a complete formulation of the Ramsey problem and then by showing that its allocations are equivalent to those obtained by solving the "relaxed" version of the problem.

$$
\max _{c_{t}, q_{t}, B_{t}, l_{t}, v_{t}, L_{t+1}} \sum_{t=0}^{\infty} \beta^{t} U\left(c_{t}, l_{t}\right)
$$

$$
\text { s.t } \quad c_{t}+L_{t}+p^{v} v_{t} \leq z_{t} F\left(1, v_{t}, l_{t}\right)+\frac{L_{t+1}}{R} \quad\left(\lambda_{t}^{p}\right)
$$

$$
\begin{gathered}
\frac{L_{t+1}}{R}+\theta p^{v} v_{t} \leq m\left(q_{t}+B_{t}\right) \quad\left(\mu_{t}^{p}\right) \\
q_{t} U_{c, t}=\beta E_{t} U_{c, t+1}\left[q_{t+1}+F_{k, t+1}+m_{t+1} \mu_{t+1} q_{t+1}\right] \\
B_{t}=\beta E_{t} \frac{U_{c, t+1}}{U_{c, t}}\left(1+m_{t+1} \mu_{t+1}\right) B_{t+1} \quad\left(\psi_{t}\right) \\
z_{t} F_{l, t}=G_{l, t} \quad\left(\varphi_{t}\right) \\
U_{c, t}=\beta R U_{c, t+1}\left(1+\tau_{t}\right)+\mu_{t} \quad\left(\gamma_{t}\right) \\
z_{t} F_{v, t}=p^{v}\left(1+\theta \mu_{t}\right) \quad\left(\eta_{t}\right) \\
\mu_{t} \geq 0 \\
\mu_{t}\left(\frac{L_{t+1}}{R}+\theta p^{v} v_{t}-m_{t} q_{t}-B_{t}\right)=0
\end{gathered}
$$

Proposition 4. Constraints A.26)-A.28 of the "fully" constrained problem are not binding for the social planner. Therefore the solution to the problem yields equivalent results to those of the "relaxed" Ramsey problem.

Proof. The proof of this proposition consists in analyzing the first order optimality conditions of "fully" constrained planner with respect to $\tau_{t}, \mu_{t}$, and $l_{t}$, and showing that the omitted equations (A.26)-A.28) do not bind for the planner. The first order conditions with respect to $\tau_{t}$ is given by $\gamma_{t} \beta R E_{t} U_{c, t+1}$, from which it follows $\gamma_{t}=0$. The first order condition with respect to $\mu_{t}$ is given by $\gamma_{t}=\eta_{t} p^{v} \theta$, from which it follows that $\eta_{t}=0$. Finally, taking a first order condition with respect to labor (taking into account that $\gamma_{t}=\eta_{t}=0$, yields 
(A.31)

$U_{c, t} G_{l, t}+\lambda_{t}^{p}-\varphi_{t}\left(G_{l l, t}-F_{l l, t}\right)-\xi_{t} q_{t} U_{c l, t}-\psi_{t} E_{t} \frac{U_{c, t+1}}{U_{c, t}}\left(1+m_{t+1} \mu_{t+1}\right) B_{t+1} \frac{U_{c l, t}}{U_{c, t}}=0$.

Substituting the first order condition with respect to consumption 26) in A.31, and using the properties of the utility function, yields $G_{l, t}=F l$, t, hence $\varphi_{t}=0$.

\section{A.5 Numerical Algorithm}

Competitive equilibrium. We solve the CE using an Euler-equation iteration algorithm. In each iteration, we solve the system of equations presented below in a recursive form for each of 1800 gridpoints: 150 values of debt $(L)$, and 12 states $(\omega: 3$ productivity states $\times 2$ collateral constraint states $\times 2$ bubble states, i.e. bubble or no-bubble). Formally, we solve for the policy functions $\{\tilde{L}(L, \omega), C(L, \omega), Q(L, \omega), b(L, \omega), \tilde{l}(L, \omega), \nu(L, \omega), \mu(L, \omega)\}, \mathcal{B}(L, \omega)$ such that:

$$
C(L, \omega)+L+p^{v} \nu(L, \omega)=z F(1, \nu(L, \omega), \tilde{l}(L, \omega))+\frac{\tilde{L}(L, \omega)}{R},
$$

$$
\frac{\tilde{L}(L, \omega)}{R}+\theta p^{v} \nu(L, \omega) \leq m(Q(L, \omega)+\mathcal{B}(L, \omega)),
$$

where

$$
\mathcal{B}(L, \omega)=\beta E_{\omega^{\prime} \mid \omega}\left(\frac{U_{c}\left(C\left(L^{\prime}, \omega^{\prime}\right)-G\left(\tilde{l}\left(L^{\prime}, \omega^{\prime}\right)\right)\right)}{U_{c}(C(L, \omega)-G(\tilde{l}(L, \omega)))} b\left(L^{\prime}, \omega^{\prime}\right)\right)
$$

$$
\begin{gathered}
b(L, \omega)=(1+m \mu(L, \omega)) \beta E_{\omega^{\prime} \mid \omega}\left(\frac{U_{c}\left(C\left(L^{\prime}, \omega^{\prime}\right)-G\left(\tilde{l}\left(L^{\prime}, \omega^{\prime}\right)\right)\right)}{U_{c}(C(L, \omega)-G(\tilde{l}(L, \omega)))} b\left(L^{\prime}, \omega^{\prime}\right)\right) \\
\mu(L, \omega)=1-\beta R E_{\omega^{\prime} \mid \omega} \frac{U_{c}\left(C\left(L^{\prime}, \omega^{\prime}\right)-G\left(\tilde{l}\left(L^{\prime}, \omega^{\prime}\right)\right)\right)}{U_{c}(C(L, \omega)-G(\tilde{l}(L, \omega)))}
\end{gathered}
$$

$$
\begin{aligned}
& Q(L, \omega) U_{c}(C(L, \omega)-G(\tilde{l}(L, \omega)))=\beta E_{\omega^{\prime} \mid \omega}\left[U_{c}\left(C\left(L^{\prime}, \omega^{\prime}\right)-G\left(\tilde{l}\left(L^{\prime}, \omega^{\prime}\right)\right)\right) \times\right. \\
& \left.\left(Q\left(L^{\prime}, \omega^{\prime}\right)+z^{\prime} F_{k}\left(1, \nu\left(L^{\prime}, \omega^{\prime}\right), \tilde{l}\left(L^{\prime}, \omega^{\prime}\right)\right)+m^{\prime} \mu\left(L^{\prime}, \omega^{\prime}\right) Q\left(L^{\prime}, \omega^{\prime}\right)\right)\right]
\end{aligned}
$$

$$
\begin{gathered}
z F_{l}(1, \nu(L, \omega), \tilde{l}(L, \omega))=G_{l}(L, \omega), \\
z F_{v}(1, \nu(L, \omega), \tilde{l}(L, \omega))=p^{v}(1+\theta \mu(L, \omega)),
\end{gathered}
$$


where $L^{\prime}=\tilde{L}(L, \omega)$. Also, $b(L, \omega)=0$ when there is no bubble. Following the first iteration, where a guess is made for each of the policy functions $\tilde{L}(L, \omega)$, $C(L, \omega), Q(L, \omega), \tilde{l}(L, \omega), \nu(L, \omega), \mu(L, \omega)$, in every iteration, the above system of equations is solved using previous-iteration solution instead of $\tilde{L}\left(L^{\prime}, \omega^{\prime}\right), C\left(L^{\prime}, \omega^{\prime}\right)$, $Q\left(L^{\prime}, \omega^{\prime}\right), \tilde{l}\left(L^{\prime}, \omega^{\prime}\right), \nu\left(L^{\prime}, \omega^{\prime}\right), \mu\left(L^{\prime}, \omega^{\prime}\right)$. The bubble equation is solved assuming that in the previous period the size of the bubble was $8 \%$ of the price of capital. In other words, we set $b(L, \omega)$ to a fixed, constant value across iterations, and use it to update $\mathcal{B}$ through equations A.5 -A.37).

In each iteration, for each grid point we first assume that the collateral constraint A.32 is binding and solve for policy functions under this assumption. This is later verified by checking if $\mu(L, \omega)=1-\beta R E_{\omega^{\prime} \mid \omega} \frac{U_{c}\left(C\left(L^{\prime}, \omega^{\prime}\right)-G\left(\tilde{l}\left(L^{\prime}, \omega^{\prime}\right)\right)\right)}{U_{c}(C(L, \omega)-G(\tilde{l}(L, \omega)))}$ is larger than zero. If for a given gridpoint $\mu(L, \omega)=0$, the system of equations is re-solved, this time imposing $\mu(L, \omega)=0$ and that the collateral constraint is not binding.

The algorithm is stopped when convergence is achieved, i.e. when for two consecutive iterations $i-1$ and $i$ it holds that $\sup _{L, \omega}\left\|x_{i}(L, \omega)-x_{i-1}(L, \omega)\right\|<\varepsilon$, where $x=\tilde{L}, C, Q, \tilde{l}, \nu, \mu, \mathcal{B}(L, \omega)$.

Social planner. We solve for the SP policy functions using a value function iteration algorithm. We use fixed-grid optimization procedure, and in each iteration we solve the value function representation of the SP's optimization problem:

$$
\begin{gathered}
V(L, \omega)=\max _{\tilde{L}, C, \tilde{l}, \nu, Q, B, \mu}\left(U(C(L, \omega)-G(\tilde{l}(L, \omega)))+\beta E_{\omega^{\prime} \mid \omega}\left[V\left(L^{\prime}, \omega^{\prime}\right)\right]\right) \\
C(L, \omega)+L+p^{v} \nu(L, \omega)=z F(1, \nu(L, \omega), \tilde{l}(L, \omega))+\frac{\tilde{L}(L, \omega)}{R}
\end{gathered}
$$

$$
\frac{\tilde{L}(L, \omega)}{R}+\theta p^{v} \nu(L, \omega) \leq m(Q(L, \omega)+\mathcal{B}(L, \omega))
$$

where

$$
\mathcal{B}(L, \omega)=\beta E_{\omega^{\prime} \mid \omega}\left(\frac{U_{c}\left(C\left(L^{\prime}, \omega^{\prime}\right)-G\left(\tilde{l}\left(L^{\prime}, \omega^{\prime}\right)\right)\right)}{U_{c}(C(L, \omega)-G(\tilde{l}(L, \omega)))} b\left(L^{\prime}, \omega^{\prime}\right)\right)
$$

$$
b(L, \omega)=(1+m \mu(L, \omega)) \beta E_{\omega^{\prime} \mid \omega}\left(\frac{U_{c}\left(C\left(L^{\prime}, \omega^{\prime}\right)-G\left(\tilde{l}\left(L^{\prime}, \omega^{\prime}\right)\right)\right)}{U_{c}(C(L, \omega)-G(\tilde{l}(L, \omega)))} b\left(L^{\prime}, \omega^{\prime}\right)\right)
$$

A.38) $Q(L, \omega) U_{c}(C(L, \omega)-G(\tilde{l}(L, \omega)))=\beta E_{\omega^{\prime} \mid \omega}\left[U_{c}\left(C\left(L^{\prime}, \omega^{\prime}\right)-G\left(\tilde{l}\left(L^{\prime}, \omega^{\prime}\right)\right)\right) \times\right.$

$$
\left.\left(Q\left(L^{\prime}, \omega^{\prime}\right)+z^{\prime} F_{k}\left(1, \nu\left(L^{\prime}, \omega^{\prime}\right), \tilde{l}\left(L^{\prime}, \omega^{\prime}\right)\right)+m^{\prime} \mu\left(L^{\prime}, \omega^{\prime}\right) Q\left(L^{\prime}, \omega^{\prime}\right)\right)\right]
$$




$$
z F_{l}(1, \nu(L, \omega), \tilde{l}(L, \omega))=G_{l}(L, \omega)
$$

$$
z F_{v}(1, \nu(L, \omega), \tilde{l}(L, \omega))=p^{v}(1+\theta \mu(L, \omega))
$$

where $V(L, \omega)$ is the value function. We use policy functions from the CE problem as starting points in the first iteration. As in the CE case, we solve for $V(L, \omega), \tilde{L}(L, \omega), C(L, \omega), Q(L, \omega), \tilde{l}(L, \omega), \nu(L, \omega), \mu(L, \omega), \mathcal{B}(L, \omega)$ using previous-iteration solution to policy functions instead of $V\left(L^{\prime}, \omega^{\prime}\right), \tilde{L}\left(L^{\prime}, \omega^{\prime}\right), C\left(L^{\prime}, \omega^{\prime}\right)$, $Q\left(L^{\prime}, \omega^{\prime}\right), \tilde{l}\left(L^{\prime}, \omega^{\prime}\right), \nu\left(L^{\prime}, \omega^{\prime}\right), \mu\left(L^{\prime}, \omega^{\prime}\right)$, and assuming $b(L, \omega)$ is fixed at a value calibrated to $8 \%$ of previous-period price of capital.

In each iteration $i$, for each gridpoint $j$, we first assume that the collateral constrain A.36 does not bind (i.e. $\mu(L, \omega)=0$ ), and solve for $L^{*}(L, \omega)$ maximizing the problem A.34 -after using the budget constraint A.35 to substitute out $C(L, \omega)$. Then the assumption that the collateral constraint is not binding is verified by checking whether $L^{*}(L, \omega)$ is lower than the borrowing limit consistent with A.36). If for a given gridpoint $L_{i, j}^{*} \geq R\left(\left(m_{i, j}\left(Q_{i, j}+L_{i, j}\right)-\theta p^{v} \nu_{i, j}\right)\right.$, we solve the problem again, this time using that A.36) should hold with equality. In particular, we use an additional grid of debt (of size $\mathrm{N}=300$ ) where for each value of debt, we derive values of $C, Q, \tilde{L}, l, \nu, \mu, \mathcal{B}$ satisfying equations A.35)-A.41) (with A.36 holding with equality) and calculate $V$ as $V=$ $U(C(L, \omega)-G(l(L, \omega)))+\beta E_{\omega^{\prime} \mid \omega}\left[V\left(L^{\prime}, \omega^{\prime}\right)\right]$. Then, the point for which $V$ is the highest is chosen as representing the optimal policy functions in the gridpoint $j$.

The algorithm is stopped when convergence is achieved, i.e. when for two consecutive iterations $i-1$ and $i$ it holds that $\sup _{L, \omega}\left\|x_{i}(L, \omega)-x_{i-1}(L, \omega)\right\|<\varepsilon$, where $x=\tilde{L}, C, Q, l, \nu, \mu$. 